\title{
An asthmatic bird lover with dyspnoea and ground glass opacities (hypersensitivity pneumonitis)
}

\author{
Krivokuca $\mathbf{I}^{* *}$ and Lammers $\mathrm{JWJ}^{2}$ \\ ${ }^{1}$ Department of Respiratory Medicine, MC Zuiderzee Hospital Lelystad, 8233 AA Lelystad, The Netherlands \\ ${ }^{2}$ Department of Respiratory Medicine, Division of Heart \& Lungs, University Medical Centre Utrecht, Heidelberglaan, The Netherlands
}

\begin{abstract}
Chronic repetitive exposure to different inhaled antigens such as feathers, droppings and serum proteins of different birds increase the risk for hypersensitivity pneumonitis (hp). We briefly describe here a 59-year-old immunocompetent female bird lover with chronic dyspnoea due to hypersensitivity pneumonitis.
\end{abstract}

\section{Case}

A 59-year-old immunocompetent woman with a history of bronchial asthma and pulmonary embolism presented to our emergency department with chronic dyspnoea. She does not smoke, and she has a pet at home (a bird), but no allergies. She has been treated for a few days with prednisone (to treat asthma) but her symptoms persisted, and she was referred for further treatment.

\section{Findings}

Her respiratory rate was 18 breaths/min and her $\mathrm{SpO} 2$ was $98 \%$ while breathing ambient air. She had no fever $\left(36.8^{\circ} \mathrm{C}\right)$ and examination of the lungs revealed normal vesicular breath sounds, without wheezing.

\section{Diagnostic studies}

A WBC count was $6.8 \times 109 / 1$ and her CRP level were $6.3 \mathrm{mg} / \mathrm{L}$. Arterial blood gas analysis showed low blood oxygen: $\mathrm{pH} 7.47, \mathrm{PaO} 2$ $69 \mathrm{~mm} \mathrm{Hg}, \mathrm{PaCO} 232 \mathrm{~mm} \mathrm{Hg}$. A normal chest x-ray (Figure 1) and a high Wells critera were the reason we wanted to rule out pulmonary embolism. A CTA thorax revealed ground-glass opacities (ggo) but no pulmonary embolism (Figure 2).

\section{Clinical course}

We admitted this patient for bronchoalveolar lavage (BAL) which showed a lymphocytic alveolitis which is usually found in HP and we measured serum bird specific IgG antibodies (precipitins). Levels of IgG antibodies (precipitins) were elevated. Previously measured IgE levels were low (it is well known that HP is a non-IgE mediated hypersensitivity). She gave her bird reluctantly away and recovered fully within five weeks in the absence of exposure to her pet. Ggo's were also completely reversible after removal from exposure. Reed et al. described the first avian-associated HP in a pigeon breeder, in 1965 [1]. Chronic repetitive exposure to different inhaled antigens such as bird excreta (droppings), and feathers of different birds, increases the risk for hypersensitivity pneumonitis [2]. Wind instrument players or even users of continuous positive airway pressure equipment could develop HP $[3,4]$. There is no diagnostic gold standard, so the current diagnosis depends on symptoms (cough, dyspnea) in a person exposed to environmental antigens, HRCT with bilateral, ground glass opacities in lower and the middle zones, bronchioloalveolar lavage fluid with lymphocytic alveolitis and high levels of IgG antibodies (precipitins).

\section{Differential diagnosis of patients with ggo's is broad}

- pneumocystis jiroveci pneumonia, PJP is an opportunistic pneumonia that occurs in immunosuppressed persons. Our patient was HIV negative and did not use any drugs which could lead to pjp.

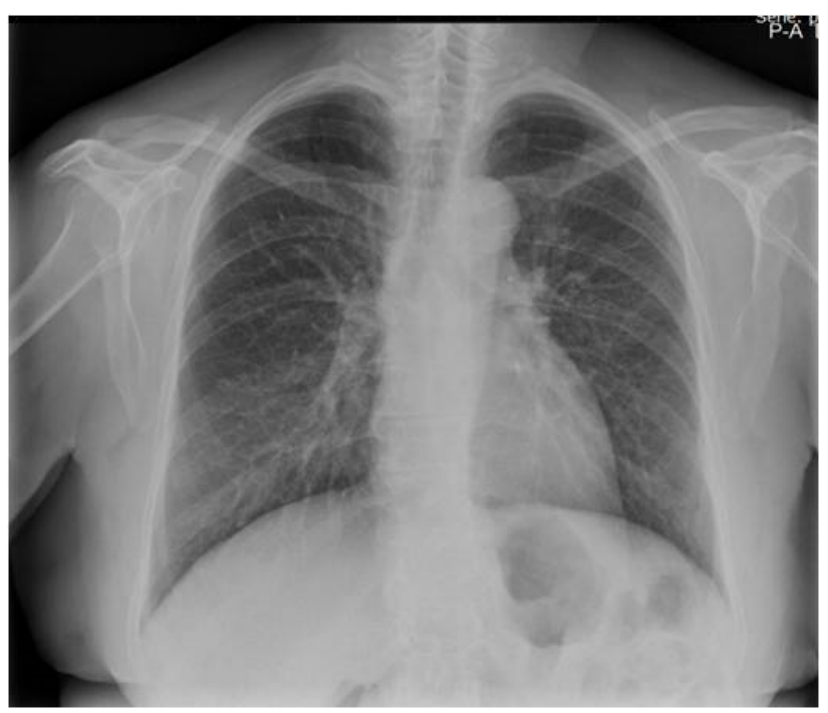

Figure 1. Chest radiograph on admission

${ }^{\star}$ Correspondence to: Krivokuca I, Department of Respiratory Medicine, MC Zuiderzee Hospital Lelystad, 8233 AA Lelystad, The Netherlands, Tel: 0031320271911,0031887556180; E-mail: sciencia0@yahoo.com

Key words: hypersensitivity pneumonitis, ground glass opacities, bird lover, IgG hypersensitivity

Received: February 26, 2019; Accepted: March 15, 2019; Published: March 20, 2019 


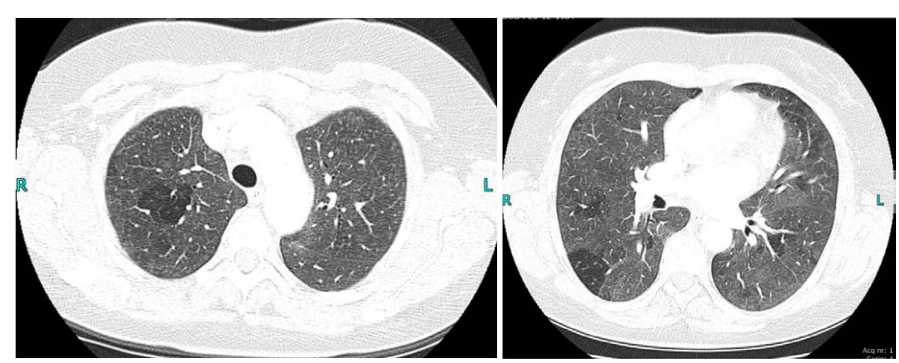

Figure 2. CTA Thorax with ground glass opacities

- viral pneumonia with no fever or cough is unusual.

- cryptogenic organizing pneumonia without the presence of patchy infiltrate and consolidation and with lymphocytic alveolitis is unusual [5].

- hypersensitivity pneumonitis may lead to ground-glass opacities on CT thorax, with a lymphocytosis in BAL fluid and elevated levels of specific serum IgG antibodies against certain antigens.

An absence of exposure to certain antigens results in full recovery.

These findings support the diagnosis of a hp [6].

\section{Conclusion}

Therefore, we should conclude that hypersensitivity pneumonitis is a diagnosis that should be considered by physicians in all bird-lovers with dyspnoea. To ask about pets, should not be forgotten in all patients with dyspnoea. Besides hypersensitivity pneumonitis is a non-IgE mediated hypersensitivity but IgG hypersensitivity with precipitins, so a low IgE level does not exclude hypersensitivity pneumonitis and dyspnoea in an asthmatic patient is not always due to asthma, it could be due to hypersensitivity pneumonitis (especially in bird lovers).

\section{References}

1. Reed CE, Barbee RA (1965) Pigeon-breeders' lung: a newly observed interstitial pulmonary disease. JAMA 193: 261-265. [Crossref]

2. Chandra D, Cherian SV (2019) Hypersensitivity Pneumonitis. Stat Pearls [Crossref]

3. Chang HC, Lan CC, Wu YK, Su WL, Yang MC (2018) Hypersensitivity pneumonitis due to unclean continuous positive airway pressure equipment. Clin Respir J 12: 17211724 [Crossref]

4. Lodha S, Sharma OP (1988) Hypersensitivity pneumonitis in a saxophone player Chest 93:1322. [Crossref]

5. Lazor R (2007) Cryptogenic and secondary organizing pneumonia. Rev Prat 57: 2243 2248. [Crossref]

6. Baur X, Fischer A, Budnik LT (2015) Spotlight on the diagnosis of extrinsic allergic alveolitis (hypersensitivity pneumonitis). J Occup Med Toxicol 10: 15. [Crossref]

Copyright: ( 2019 Krivokuca I. This is an open-access article distributed under the terms of the Creative Commons Attribution License, which permits unrestricted use, distribution, and reproduction in any medium, provided the original author and source are credited. 